Int. J. Electrochem. Sci., 12 (2017) 2593 - 2605

International Journal of

ELECTROCHEMICAL

SCIENCE

www.electrochemsci.org

\title{
Effect of Rotating Speed and Hydrostatic Pressure on Erosion- Corrosion Behavior of X65 Pipeline Steel
}

\author{
Qiongbin Zheng, Liuyan Zhang ${ }^{*}$, Xiaohua Jie ${ }^{*}$, Xiaoye Huang, Song Luo
}

School of Materials and Energy, Guangdong University of Technology, Guangzhou 510006, PR China *E-mail: zlyjust@gdut.edu.cn (Liuyan Zhang); cnxyyz3@gdut.edu.cn (Xiaohua Jie)

doi: $10.20964 / 2017.03 .10$

Received: 30 November 2016 / Accepted: 8 January 2017 / Published: 12 February 2017

A simple rotating experimental setup with adjustable rotating speed and hydrostatic pressure was established to simulate the erosion-corrosion environment. The effect of rotating speed and hydrostatic pressure on the erosion-corrosion behavior of X65 steel in 3.5 mass $\% \mathrm{NaCl}$ was investigated by polarization, electrochemical impedance spectroscopy, and scanning electron microscopy. The results revealed that the rotating speed changed the corrosion type of X65 steel from a pure uniform electrochemical corrosion into the combination of uniform corrosion and local damage, which was aggravated with increasing the rotating speed. The hydrostatic pressure has the opposite effect on the uniform and local corrosion of X65 steel, showing a decrease of uniform corrosion and an increase of local damage.

Keywords: X65 steel; rotating speed; hydrostatic pressure; erosion-corrosion; local damage

\section{$\underline{\text { FULL TEXT }}$}

(C) 2017 The Authors. Published by ESG (www.electrochemsci.org). This article is an open access article distributed under the terms and conditions of the Creative Commons Attribution license (http://creativecommons.org/licenses/by/4.0/). 